\title{
Root replacement in acute dissection type A-A superior procedure?
}

\author{
Hans-Joachim Schäfers, MD
}

\footnotetext{
From the Department of Thoracic and Cardiovascular Surgery, Saarland University Medical Center, Homburg/ Saar, Germany.

Disclosures: Author has nothing to disclose with regard to commercial support.

Received for publication Sept 8, 2017; accepted for publication Sept 9, 2017; available ahead of print Oct 5, 2017. Address for reprints: Hans-Joachim Schäfers, MD, Department of Thoracic and Cardiovascular Surgery, Saarland

University Medical Center, Homburg/Saar, Germany (E-mail: h-j.schaefers@uks.eu).

J Thorac Cardiovasc Surg 2018;155:8-9

$0022-5223 / \$ 36.00$

Copyright (C) 2017 by The American Association for Thoracic Surgery

https://doi.org/10.1016/j.jtcvs.2017.09.038
}

Aortic dissection type A (AADA) has continued to be a challenging disease for surgeons. Despite improvements in the surgical armamentarium over the past decades, considerable early morbidity and mortality persists. Several studies have shown that after successful initial treatment there is still a relevant late mortality and also the need for reoperation in a proportion of patients. ${ }^{1,2}$

Two main factors have been associated with the occurrence of late complications, ie, persistent perfusion of the distal false lumen and instability of the root with secondary dilatation or aortic regurgitation requiring reoperation. It has been known that patients with connective tissue disease are particularly prone to develop late aortic complications, ${ }^{1-3}$ and particularly for this scenario, aggressive root replacement has become an accepted approach. In the past years there has been a trend toward proposing more aggressive surgery, ie, primary root replacement with or without valve preservation.

Nonetheless, at times there is discrepancy between proposals form single surgeons and the real-world scenario. In this context, Chiu and coworkers ${ }^{4}$ have analyzed the results of surgical treatment of AADA in a recent period. In a large cohort of patients with AADA, they compared the outcomes of primary root replacement with those of limited root repair. Early and late mortality was almost identical; thus, aggressive root replacement neither increased early mortality nor improved late survival. They did observe a greater incidence of need for reoperation after limited root repair, which they considered as a main conclusion.

Should surgeons thus be generally more aggressive with root replacement in the setting of AADA? The answer is not as easy as the title of the publication. ${ }^{4}$ The incidence of reoperation at 10 years postoperatively was less than $10 \%$ with less than $5 \%$ of patients at risk, limiting the clinical relevance of the analysis. ${ }^{4}$ The procedures done as "limited root repair" were not homogenous, further limiting conclusions that can be drawn from the findings. ${ }^{4}$ With the limited patient data and information on predissection aortic size, it is impossible to determine whether and what degree of surgeons.

\section{References} 92( 9 suppl):II113-21.

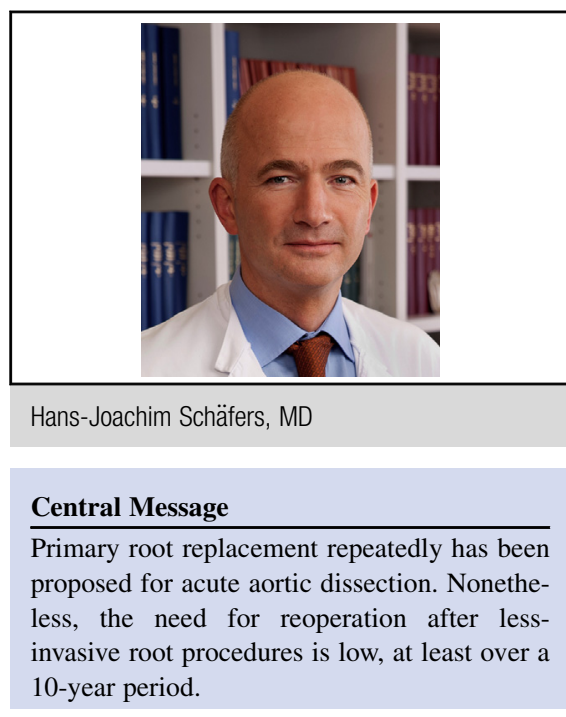

See Article page 1.

preexistent pathology predisposes to instability of the root. $^{4}$ Finally, it is unclear whether the low mortality of composite replacement depends on the work of selected

In drawing clinical conclusions from the analysis, it must be kept in mind that the goal of surgery in AADA is to avert the life-threatening consequences of the disease and keep the patient alive. Root replacement in this setting increases the complexity of the operation and in the current study did not show any positive effect on long-term survival. ${ }^{4}$

Thus, the general wisdom in treating AADA remains, in that aggressive root replacement with or without valve preservation may be justified in selected instances if the surgeon has experience in this form of surgery. ${ }^{5,6}$ Until new evidence is generated, the results of more conservative procedures have to be considered as sufficient in most instances, and the surgeon should not feel compelled to perform complex procedures in an emergency setting.

1. Fann JI, Smith JA, Miller DC, Mitchell RS, Moore KA, Grunkemeier G, et al. Surgical management of aortic dissection during a 30-year period. Circulation. 1995;

2. Chiu P, Miller DC. Evolution of surgical therapy for Stanford acute type A aortic dissection. Ann Cardiothorac Surg. 2016;5:275-95.

3. Haverich A, Miller DC, Scott WC, Mitchell RS, Oyer PE, Stinson EB, et al. Acute and chronic aortic dissections-determinants of long-term outcome for operative survivors. Circulation. 1985;72:II22-34. 
4. Chiu P, Trojan J, Tsou S, Goldstone AB, Woo YJ, Fischbein M. Limited root repair in acute type A dissection is safe but results in increased risk of reoperation. J Thorac Cardiovasc Surg. 2018;155:1-7.e1.

5. Kunihara T, Neumann N, Kriechbaum SD, Aicher D, Schäfers HJ. Aortic root remodeling leads to good valve stability in acute aortic dissection and preexistent root dilatation. J Thorac Cardiovasc Surg. 2016;152: 430-6.

6. Halstead JC, Spielvogel D, Meier DM, Rinke S, Bodian C, Malekan R, et al. Composite aortic root replacement in acute type A dissection: time to rethink the indications? Eur J Cardiothorac Surg. 2005;27:626-32; discussion 632-3. 